\title{
Footwear width and balance-recovery reactions: A new approach to improving lateral stability in older adults
}

\author{
Takeshi Yamaguchi PhD ${ }^{\mathrm{a}, \mathrm{b}, \mathrm{c}}$ \\ Kenneth C. Cheng PhD ${ }^{b, c, d, f}$ \\ Sandra M. McKay PhD ${ }^{b, c, g}$ \\ Brian E. Maki PhD ${ }^{\mathrm{b}, \mathrm{c}, \mathrm{e}}$
}

\begin{abstract}
${ }^{a}$ Graduate School of Engineering, Tohoku University, Sendai, Miyagi, Japan, E: yamatake@gdl. mech.tohoku.ac.jp; ${ }^{b}$ Toronto Rehabilitation Institute-University Health Network, Toronto, ON, Canada, E: brian.maki@uhn.ca; 'Sunnybrook Health Sciences Centre, Toronto, ON, Canada; ${ }^{\text {IIn- }}$ stitute of Medical Science, University of Toronto, Toronto, ON, Canada; 'Department of Surgery, Institute of Biomaterials and Biomedical Engineering, and Institute of Medical Science, University of Toronto, Toronto, ON, Canada; 'Department of Sports Science and Physical Education, Faculty of Education, The Chinese University of Hong Kong, Shatin, NT, Hong Kong, China; E: kchengc@ cuhk.edu.hk; ${ }^{g} V H A$ Home HealthCare, Toronto, ON, Canada; E: smckay@vha.ca
\end{abstract}

\begin{abstract}
T. Yamaguchi, K.C. Cheng, S.M. McKay, B.E. Maki. Footwear width and balance-recovery reactions: A new approach to improving lateral stability in older adults. Gerontechnology 2015;13(3):359-367; doi:10.4017/gt.2015.13.3.008.00 Background Age-related difficulty in controlling lateral stability is of crucial importance because lateral falls increase risk of debilitating hip-fracture injury. This study examined whether a small increase in footwear sole width can improve ability of older adults to regain lateral stability subsequent to balance perturbation. Methods The study involved sixteen healthy, ambulatory, community-dwelling older adults (aged 65-78). Widened base-of-support (WBOS) footwear was simulated by affixing polystyrene-foam blocks (20mm wide) on the medial and lateral sides of rubber overshoes; unaltered overshoes were worn in normal (NBOS) trials. Balance perturbations were applied using a motion platform. Results Gait, mobility and agility tests revealed no adverse effects of wearing the WBOS footwear. Lateral-perturbation tests showed that the WBOS footwear improved ability to stabilize the body without stepping $(p=0.002)$. Depending on the perturbation magnitude, the frequency of stepping was reduced by up to $25 \%(64 \%$ of NBOS trials vs $39 \%$ of WBOS trials). In addition, the WBOS footwear appeared to improve ability to maintain lateral stability during forward-step reactions, as evidenced by reduced incidence of additional lateral steps $(p=0.04)$ after stepping over an obstacle in response to a forward-fall perturbation. Conclusions A small increase in sole width can improve certain aspects of lateral stability in older adults, without compromising mobility and agility. This finding supports the viability of WBOS footwear as an intervention to improve balance. Further research is needed to test populations with more severe balance impairments, examine user compliance, and determine if WBOS footwear actually reduces falling risk in daily life.
\end{abstract}

Keywords: aging, balance perturbation, compensatory stepping, fall prevention, footwear

Difficulty in controlling balance is a major concern for increased risk of falls and fall-related injuries in older adults. In particular, age-related difficulty in controlling lateral stability is of crucial importance because lateral falls increase risk of debilitating hip-fracture injury ${ }^{1,2}$.

A fall occurs when the balance-recovery reactions fail to fully counter the destabilization caused by a perturbation such as a slip, trip or collision $^{3}$. To maintain postural stability, the displacement and the velocity of the body center of mass (COM) must be regulated within the stability limits of the base of support (BOS) defined by the feet (as well as the hands, when touching an object for support) ${ }^{3-6}$. Stabilizing reactions to balance perturbations must therefore involve deceleration of the COM with respect to the existing BOS stability limits (via generation of appropriate joint torques) or limb movements to alter the BOS (via rapid stepping or reach-to-grasp movements).

Older adults often appear to experience difficulty in responding to lateral balance perturbation $^{7-14}$, and a number of these difficulties have been found to predict increased risk of falling in daily life $\mathrm{i}^{7-11}$. Older adults tend to be less able than younger persons to maintain upright stance without exceeding their BOS stability limits, i.e. without stepping or grasping for support $^{12}$. Furthermore, older adults often appear to 
experience difficulty when stepping in response to lateral perturbation, as evidenced by:(i) an increased likelihood of collisions between the stepping foot and the stance limb, (ii) a tendency to avoid crossover steps, and (iii) a higher incidence of multiple-step responses ${ }^{7,8,11,13,14}$. In addition, when stepping in response to anteroposterior perturbation, older adults often seem to experience difficulty in maintaining lateral stability during the initial step, thereby necessitating additional steps in the lateral direction $7,8,15,16$.

In theory, footwear that increases the lateral BOS limits could help compensate for age-related difficulties in maintaining lateral stability, and thereby reduce risk of falling. Such an increase in BOS width would accommodate increased lateral COM excursion without loss of stability, and allow an additional time margin for the COM to reach the BOS limits ${ }^{3}$. In addition, it could enable larger stabilizing moments to be generated by allowing increased displacement of the centre of foot pressure (COP) in relation to the $\mathrm{COM}^{3,17}$. Such effects could possibly improve ability to withstand perturbations without stepping and reduce the number of steps required when stepping to regain equilibrium. On the other hand, excessive widening of the footwear might exacerbate difficulties in avoiding limb collisions when stepping laterally, and could also have other adverse effects on mobility and agility.

Previous research has shown that features of footwear design, such as heel height ${ }^{18,19}$, heel collar height ${ }^{20}$, and sole thickness and hard- a)

Footwear with normal sole
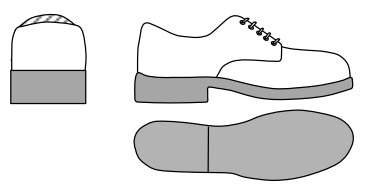

Footwear with widened sole (flared sole)
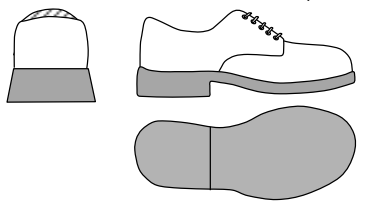

Footwear with widened sole (no flaring)
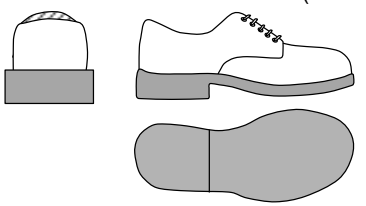
widened outsoles (with or without flaring of the outsole); (b) approach used in this study to simulate the effects of widening the shoe outsole (i.e. taping of polystyrene blocks onto rubber overshoes)
Figure 1. Widened base-of-support (WBOS) footwear: (a) shoes incorporating ness ${ }^{21}$, can have an impact on various aspects of balance. Of particular relevance here is a study that examined the effect of flaring of the outer sole in community-dwelling older adults ${ }^{22}$. Flaring of $20^{\circ}$ increased the BOS width by $5 \mathrm{~mm}$ on each side of the foot (Figure 1a), but was found to have no effects on postural sway, maximal balance range, coordinated stability and choicestepping reaction time ${ }^{22}$. However, this study did reactions. To the authors' knowledge, there are no studies in the literature that have evaluated the effect of footwear width on the efficacy of balance-recovery reactions evoked by unpredictable balance perturbation.

The objective of this initial 'proof-of-principle' study was to determine whether a small increase in footwear width $(20 \mathrm{~mm}$ medially plus $20 \mathrm{~mm}$ laterally) can improve ability of older adults to regain lateral stability after experiencing a balance perturbation. Unpredictable balance perturbations were delivered using motion-platform translation, and each subject was tested while wearing normal BOS (NBOS) footwear and widened BOS (WBOS) footwear. We hypothesized that the widened BOS footwear would improve lateral stability of older adults during: (i) natural reactions evoked by lateral perturbation (fewer multiple-step responses); (ii) constrained 'try not to step' reactions to lateral perturbation (increased ability to recover balance without stepping); and (iii) stepping evoked by antero-posterior perturbation (fewer lateral-step responses). We also hypothesized that the relatively small increase not assess possible effects on balance-recovery b)

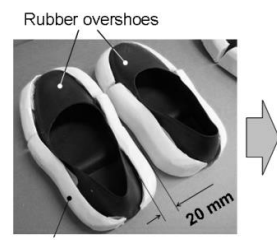

Polystyrene foam

Footwear with overshoes and polystyrene blocks
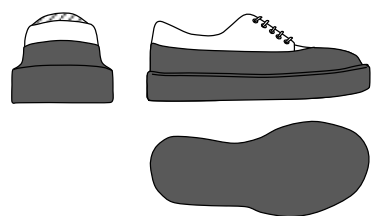
in footwear width would allow these benefits to be achieved without any adverse effects on: (i) frequency of limb collisions during lateral step reactions, or (ii) more general measures of gait and mobility/agility.

\section{Methods}

\section{Subjects}

Sixteen healthy older adults (8 men, 8 women; age 65-78 years; height $1.50-$ $1.83 \mathrm{~m}$; mass $63.5-95.3 \mathrm{~kg}$ ) participated in this experiment. All subjects were naive (no previous balance testing), lived independently in the community and were able to ambulate without any aids. Volunteers were excluded if they reported any neurological or sensory disorders, use 
Table 1. Perturbation characteristics; Each platform-translation perturbation comprised a $300 \mathrm{~ms}$ square acceleration pulse followed immediately by an equal and opposite deceleration pulse; $N=$ normal base-of-support footwear; $W=$ wide base-of-support footwear; $L=$ leftward; $R=$ rightward; $F=$ forward; $B=$ backward; $N A=n o t$ applicable

\begin{tabular}{|c|c|c|c|c|c|c|c|}
\hline \multirow{2}{*}{\multicolumn{2}{|c|}{ Trial }} & \multirow{2}{*}{ Footwear } & \multicolumn{2}{|c|}{ Perturbation characteristics } & \multirow{2}{*}{$\begin{array}{l}\text {-Stance } \\
\text { leg }\end{array}$} & \multirow{2}{*}{$\begin{array}{l}\text { Number of } \\
\text { replicates }\end{array}$} & \multirow{2}{*}{$\begin{array}{c}\text { Total } \\
\text { number of } \\
\text { trials }\end{array}$} \\
\hline & & & Direction & Magnitude & & & \\
\hline \multirow{8}{*}{$\begin{array}{l}\text { Unconstrained } \\
\text { (react naturally) }\end{array}$} & \multirow[t]{4}{*}{ Stance } & $N, W$ & $L, R$ & $2.0 \mathrm{~m} / \mathrm{s}^{2}, 0.6 \mathrm{~m} / \mathrm{s}$ & Bipedal & 6 & 24 \\
\hline & & $\mathrm{N}, \mathrm{W}$ & $\mathrm{L}, \mathrm{R}$ & $1.0 \mathrm{~m} / \mathrm{s}^{2}, 0.3 \mathrm{~m} / \mathrm{s}$ & Bipedal & 1 & 4 \\
\hline & & N, W & $\mathrm{F}, \mathrm{B}$ & $2.0 \mathrm{~m} / \mathrm{s}^{2}, 0.6 \mathrm{~m} / \mathrm{s}$ & Bipedal & 1 & 4 \\
\hline & & $N, W$ & NA & NA & Bipedal & 2 & 4 \\
\hline & \multirow[t]{4}{*}{ Walk-in-place } & $\mathrm{N}, \mathrm{W}$ & $\mathrm{L}$ & $2.0 \mathrm{~m} / \mathrm{s}^{2}, 0.6 \mathrm{~m} / \mathrm{s}$ & Right & 3 & 6 \\
\hline & & $N, W$ & $\mathrm{R}$ & $2.0 \mathrm{~m} / \mathrm{s}^{2}, 0.6 \mathrm{~m} / \mathrm{s}$ & Left & 3 & 6 \\
\hline & & $N, W$ & $\mathrm{~F}, \mathrm{~B}$ & $2.0 \mathrm{~m} / \mathrm{s}^{2}, 0.6 \mathrm{~m} / \mathrm{s}$ & Left & 1 & 4 \\
\hline & & $N, W$ & NA & NA & NA & 1 & 2 \\
\hline \multirow{5}{*}{\multicolumn{2}{|c|}{ Constrained (try not to step) }} & $N, W$ & $L, R$ & $1.0 \mathrm{~m} / \mathrm{s}^{2}, 0.3 \mathrm{~m} / \mathrm{s}$ & Bipedal & 2 & 8 \\
\hline & & N, W & $\mathrm{L}, \mathrm{R}$ & $1.5 \mathrm{~m} / \mathrm{s}^{2}, 0.45 \mathrm{~m} / \mathrm{s}$ & Bipedal & 2 & 8 \\
\hline & & $N, W$ & $L, R$ & $2.0 \mathrm{~m} / \mathrm{s}^{2}, 0.6 \mathrm{~m} / \mathrm{s}$ & Bipedal & 2 & 8 \\
\hline & & $N, W$ & $L, R$ & $2.5 \mathrm{~m} / \mathrm{s}^{2}, 0.75 \mathrm{~m} / \mathrm{s}$ & Bipedal & 2 & 8 \\
\hline & & $N, W$ & $L, R$ & $3.0 \mathrm{~m} / \mathrm{s}^{2}, 0.9 \mathrm{~m} / \mathrm{s}$ & Bipedal & 2 & 8 \\
\hline \multicolumn{2}{|c|}{ Cued forward-step } & $N, W$ & $\mathrm{~B}$ & $3.0 \mathrm{~m} / \mathrm{s}^{2}, 0.9 \mathrm{~m} / \mathrm{s}$ & $\mathrm{NA}$ & 5 & 10 \\
\hline
\end{tabular}

of medications that may affect balance, medical conditions interfering significantly with daily activities, or functional limitations of limb use. Each subject provided written informed consent to comply with ethics approval granted by the institutional review board.

\section{Preparation of widened-BOS footwear}

For the purposes of this initial 'proof-of-principle' study, we simulated the effect of wearing WBOS footwear by affixing $20 \mathrm{~mm}$-wide blocks of polystyrene foam (density $64 \mathrm{~kg} / \mathrm{m}^{3}$, compressive strength $207 \mathrm{kPa}$ ) on the medial and lateral sides of rubber overshoes (METRO, M\&B Shoe Care, Ontario, Canada) with double-sided tape and duct tape (Figure 1b). Pilot tests were performed to ensure that the taped polystyrene was sufficiently strong to withstand repeated use during the experimental protocol without sustaining any overt loosening or damage to the polystyrene. Unmodified overshoes were worn in the normal base-of-support (NBOS) trials. For both WBOS and NBOS trials, subjects wore their own comfortable, walking shoes underneath the overshoes. To ensure a secure fit, each subject was fitted with an appropriate size of overshoe [Small (US6-7), Medium (US8-9), Large (US10-11), or Extra large (USA12-13)], and packing was used (when necessary) to fill any spaces between the shoe and overshoe.

\section{Protocol}

Subjects were tested with the NBOS and WBOS footwear in separate sessions. The order of sessions was balanced across subjects.

\section{Gait and mobility tests}

Tests of preferred- and maximum-speed gait $^{23}$, tandem gait ${ }^{24}$, Timed-Up-and-Go ${ }^{25-26}$, and $180^{\circ}$ turn $^{27}$ were carried out to see if the WBOS foot- wear affected gait and mobility. In preferred- and maximum-speed gait tests, subjects were instructed to walk on a 5-m GAITRite mat (CIR Systems, $\mathrm{NJ}$, USA) at their self-selected pace (ten traverses) or at maximum speed (four traverses). Spatial and temporal step parameters were determined by the GAITRite software. In the tandem-gait tests, the time required to complete 5-m of tandem (heel to toe) gait was measured, along with the number of missteps (i.e. heel or side of leading foot does not touch toes of stance foot). The tandem gait index (TGI) was calculated as expended time $(X)$ plus twofold of mistake frequency $(\mathrm{Y})$; i.e. $\mathrm{TGl}=\mathrm{X}+2 \mathrm{Y}^{24}$. In the Timed-Up-and-Go test, subjects were timed while they rose from an arm chair, walked $3 \mathrm{~m}$, turned, walked back, and sat down again ${ }^{25}$. In the $180^{\circ}$-turn test, subjects were asked to turn $180^{\circ}$ without pivoting ${ }^{27}$, and the time and number of steps taken to complete the turn were measured.

\section{Balance-perturbations}

Postural reactions were evoked by sudden translation of a computer-controlled movable platform ${ }^{6,13}$ on which the subject stood or walked in place. The large size of the platform surface $(2 \mathrm{~m} \times 2 \mathrm{~m})$ allowed sufficient space for subjects to take two or more steps in any direction. Subjects wore a safety harness designed to prevent falling to the floor without affecting balance reactions. To deter predictive responses, the perturbations were applied unpredictably in terms of direction and time of onset. In all perturbation trials, subjects held a lightweight rod $(3 \mathrm{~cm}$ diameter, $40 \mathrm{~cm}$ length) behind the back to deter arm movement ${ }^{28}$. The perturbation characteristics are listed in Table 1 and Figure 2.

\section{Balance-perturbation protocol}

Three main blocks of balance-perturbation trials were performed:(i) 'unconstrained' reactions in 

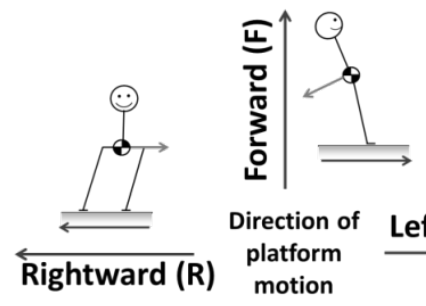

Direction of Leftward (L)
platform
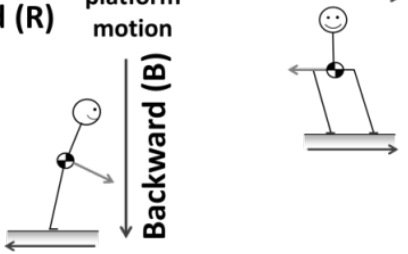

Figure 2. Schematic drawing showing the directions of the platform-motion balance perturbations and the resulting falling motion

which subjects were allowed to respond naturally, (ii) 'constrained' reactions in which subjects were asked to try not to step, and (iii) 'cued forwardstep' reactions in which subjects were required to recover balance by stepping forward over an obstacle and landing the step foot on a target. In each case, the perturbations were delivered during bipedal stance. In addition, the 'unconstrained' block included trials in which the perturbations were delivered while the subject walked in place.

The focus of the 'unconstrained' and 'constrained' trials was on the responses evoked by lateral platform perturbations, whereas the focus of the 'cued forward-step' trials was on lateral instability arising during the forward stepping evoked by backward platform translation (the obstacle and target serving to heighten this challenge to lateral stability $^{29}$ ). Additional 'wild-card' trials, involving other perturbation directions and/or magnitudes (or no perturbation at all), were interspersed during the 'unconstrained' trial blocks so as to increase unpredictability and deter predictive responses (Table 1), but were not included in any of the analyses.

In stance trials, subjects stood in a standard comfortable position $\left(14^{\circ}\right.$ angle between medial foot margins, heel-center spacing $=11 \%$ of body height ${ }^{16}$ prior to perturbation onset. For walk-inplace trials, subjects were instructed to step to the beat of metronome (100 steps/minute, step height $2-3 \mathrm{~cm}$ ) while keeping the feet within a rectangular boundary circumscribing the standard position described above; the perturbation was computer-triggered to occur at the onset of a randomly selected step (stance-foot vertical force, recorded by the platform force plates, $>90 \%$ of body weight).

The 'unconstrained' trial block comprised eighteen stance-perturbation trials [six leftward and six rightward platform translations $\left(2.0 \mathrm{~m} / \mathrm{s}^{2}, 0.6 \mathrm{~m} / \mathrm{s}\right)$, plus six 'wild-card' trials] followed by nine walkin-place trials [three leftward and three rightward platform translations $\left(2.0 \mathrm{~m} / \mathrm{s}^{2}, 0.6 \mathrm{~m} / \mathrm{s}\right)$, plus three 'wild-card' trials]. All subjects performed the same pseudorandom sequence of perturbations in each block. Subjects were instructed to look straight ahead at a visual target, to try not to move their arms, and to otherwise "do whatever comes naturally to prevent yourself from falling".

In the 'constrained' trial block, subjects were instructed to try not to step and to take as few steps as possible if they needed to step. Subjects were also instructed to try not to release the handheld rod or move their arms. To motivate the subjects, they were told that the subject who was best at avoiding stepping and arm movement would win a cash prize (CDN\$50). The magnitude of lateral perturbation (leftward and rightward) was successively incremented by $0.5 \mathrm{~m} / \mathrm{s}^{2}$ from $1.0 \mathrm{~m} / \mathrm{s}^{2}$ to $3.0 \mathrm{~m} / \mathrm{s}^{2}$ (five magnitude levels). Two rightward and two leftward platform translations were delivered at each of the five perturbation magnitudes (total of twenty trials for each footwear condition). All subjects performed the same pseudorandom sequence of perturbation directions at each magnitude.

In the 'cued forward-step' trial block, subjects were instructed to recover balance by taking a single step forward with the right foot. They were also told to avoid contact with the obstacle placed in front of them and to land the great toe on a target line (a line of red tape extending forward from the right foot). The obstacle was a narrow bar $(3.5 \mathrm{~cm}$ diameter, $150 \mathrm{~cm}$ in length) mounted transversely on the platform in front of the subject $(2.5 \%$ of body height in front of the toes) at a height equal to $12.5 \%$ of body height ${ }^{29}$. Backward platform translations $\left(3.0 \mathrm{~m} / \mathrm{s}^{2}, 0.9 \mathrm{~m} / \mathrm{s}\right)$ were used to elicit the stepping reactions, and five such trials were performed for each footwear condition (total of ten trials for each subject).

\section{Balance-perturbation measurements}

Video recordings from four high-resolution cameras were used to determine if subjects stepped in response to the lateral balance perturbation, if they took multiple steps, if they moved one or both arms (by releasing the handheld rod), or if a collision between the step foot and stance leg occurred. These videos were also used to determine whether the response involved a 'crossover' step (foot moved across the mid-sagittal plane and landed laterally with respect to the stance foot) or a 'side-step sequence' (initial small medial step followed by a lateral step with the other foot) ${ }^{6,13,28}$. The occurrence of stepping was verified from force-plate recordings, and was defined 
to occur when the vertical ground reaction force of either foot was less than $1 \%$ body weight. For the backward platform translations, we also measured whether lateral step placement occurred, by using a Vicon motion-capture system to resolve the lateral position of a reflective marker placed on the footwear (first metatarsal head) relative to markers on the motion platform.

\section{Statistical analysis}

Statistical analyses were performed to test the hypotheses that WBOS footwear would reduce the frequency of: (i) multiple-step reactions in 'unconstrained' lateral-perturbation trials; (ii) stepping reactions in 'constrained' lateral-perturbation trials; or (iii) lateral-step reactions in 'cued forward-step' trials. We also tested the hypotheses that the WBOS footwear would have no adverse effects on: (i) frequency of limb collisions during lateral step reactions, or (ii) measures of gait and agility (i.e. spatial-temporal footstep parameters, and scores on Timed-Up-and-Go, tandem gait and $180^{\circ}$-turn tests).

The statistical analyses were performed using SPSS (version 19.0, Chicago, IL, USA). For the 'constrained' trials, a two-way repeated-measures analysis of variance (ANOVA) was performed for each of the frequency measures described above, treating type of footwear (NBOS or WBOS) and perturbation magnitude (1.0, 1.5, 2.0, 2.5 or $3.0 \mathrm{~m} / \mathrm{s}^{2}$ ) as the two independent variables. For these analyses, the dependent variable was the frequency score (i.e. percentage of trials) computed within each subject, at each perturbation magnitude and for each type of footwear. For all other analyses, footwear-type was the only independent variable, and the dependent variable was either a continuous variable (e.g. Timed-
Up-and-Go score) or a frequency score that was computed within each subject for each type of footwear. For these analyses, a paired t-test was used to compare the NBOS and WBOS footwear. Significance level was set at 0.05. When appropriate, the data were rank-transformed to ensure that the assumptions associated with the ANOVA and paired t-test were met.

\section{Results}

\section{Gait and mobility tests}

WBOS footwear slightly increased stride width (by $\sim 1 \mathrm{~cm}$, on average) compared with NBOS footwear, in both preferred $(p=0.02)$ and maximum-speed tests $(p=0.01)$. Walking velocity and other spatial-temporal parameters were not affected by wearing WBOS footwear ( $p^{\prime} s>0.07$ ). There were also no significant footwear-related differences in tandem-gait, timed-up-and-go or $180^{\circ}$-turn test scores ( $\left.p^{\prime} \mathrm{s}>0.15\right)$ (Table 2).

\section{Balance-perturbation trials}

In the 'unconstrained' trials (subjects allowed to respond naturally), subjects almost always took one or more steps in response to the lateral perturbations ( $>93.2 \%$ of stance trials, $100 \%$ of walkin-place trials), regardless of the type of footwear worn. Other features of the responses were also similar for both types of footwear (Table 3). Specifically, footwear was found to have no significant effect on the frequency of trials involving multiple steps, crossover steps, side-step-sequence responses, limb collisions or arm movements, for either stance or walk-in-place trials ( $p^{\prime} s>0.23$ ).

In the 'constrained' lateral-perturbation trials (subjects instructed to try not to step), subjects were almost never able to avoid stepping at the two largest perturbation magnitudes (2.5 and

Table 2. Summary of gait and mobility test results; paired t-test ${ }^{*}=p<0.05 ; N B O S=$ Normal base-of-support; WBOS=Widened base-of-support; TGI=Tandem gait index

\begin{tabular}{|c|c|c|c|c|c|}
\hline \multirow{2}{*}{ Trial type } & & \multirow{2}{*}{ Measure } & \multicolumn{2}{|c|}{ Mean \pm SD } & \multirow{2}{*}{$p$ value } \\
\hline & & & NBOS & WBOS & \\
\hline \multirow[t]{10}{*}{ Gait } & \multirow[t]{5}{*}{ Preferred speed } & Walking velocity, $\mathrm{cm} / \mathrm{s}$ & $134 \pm 19.4$ & $13.2 \pm 23.8$ & 0.69 \\
\hline & & $\begin{array}{l}\text { Double support } \\
\text { period, } \%\end{array}$ & $25.1 \pm 2.9$ & $25.7 \pm 2.7$ & 0.20 \\
\hline & & Stride length, cm & $141 \pm 13.1$ & $142 \pm 16.5$ & 0.68 \\
\hline & & Stride time, s & $1.1 \pm 0.1$ & $1.1 \pm 0.1$ & 0.38 \\
\hline & & Stride width, cm & $12.6 \pm 3.1$ & $13.6 \pm 3.2$ & $0.02 *$ \\
\hline & \multirow[t]{5}{*}{ Maximum speed } & Walking velocity, $\mathrm{cm} / \mathrm{s}$ & $177 \pm 19.8$ & $176 \pm 20.6$ & 0.91 \\
\hline & & $\begin{array}{l}\text { Double support } \\
\text { period, \% }\end{array}$ & $21.9 \pm 2.4$ & $22.0 \pm 2.6$ & 0.85 \\
\hline & & Stride length, cm & $159 \pm 13.6$ & $162 \pm 14.4$ & 0.07 \\
\hline & & Stride time, s & $0.91 \pm 0.1$ & $0.92 \pm 0.1$ & 0.39 \\
\hline & & Stride width, $\mathrm{cm}$ & $12.1 \pm 3.5$ & $13.2 \pm 3.5$ & $0.01^{*}$ \\
\hline \multirow[t]{4}{*}{ Mobility } & Tandem gait & TGI & $25.9 \pm 11.7$ & $27.8 \pm 17.0$ & 0.60 \\
\hline & Timed Up \& Go (TUG) & Time, s & $10.1 \pm 1.9$ & $10.1 \pm 1.7$ & 0.98 \\
\hline & 180 degrees turn test & Time, s & $2.5 \pm 0.8$ & $2.7 \pm 1.0$ & 0.15 \\
\hline & & Steps taken, steps & $3.8 \pm 0.9$ & $3.9 \pm 0.9$ & 0.43 \\
\hline
\end{tabular}


Table 3. Summary of balance-perturbation test results; paired $t$-test ${ }^{*}=p<0.05$; two-way repeated-measures ANOVA $^{* *} p<0.05 ;$ NBOS=Normal base-of-support; WBOS=Widened base-of-support

\begin{tabular}{|c|c|c|c|c|c|}
\hline \multirow{2}{*}{ Trial type } & & \multirow{2}{*}{ Frequency of responses } & \multicolumn{2}{|c|}{ Mean \pm SD } & \multirow{2}{*}{$p$ value } \\
\hline & & & NBOS & WBOS & \\
\hline \multirow{12}{*}{$\begin{array}{l}\text { Unconstrained } \\
\text { (react naturally) }\end{array}$} & \multirow[t]{6}{*}{ Stance } & No step & $3.6 \pm 12.5$ & $6.8 \pm 24.9$ & 0.35 \\
\hline & & Crossover step & $12.5 \pm 21.3$ & $15.1 \pm 22.6$ & 0.43 \\
\hline & & Side-step-sequence & $50.0 \pm 44.2$ & $36.5 \pm 40.1$ & 0.23 \\
\hline & & Multiple steps & $4.7 \pm 10.5$ & $11.5 \pm 21.1$ & 0.25 \\
\hline & & Arm movement & $8.3 \pm 13.9$ & $7.3 \pm 17.2$ & 0.84 \\
\hline & & Limb collisions & $19.3 \pm 29.3$ & $13.0 \pm 20.4$ & 0.39 \\
\hline & \multirow[t]{6}{*}{ Walk-in-place } & No step & 0.0 & 0.0 & - \\
\hline & & Crossover step & $33.3 \pm 39.4$ & $37.5 \pm 35.2$ & 0.51 \\
\hline & & Side-step-sequence & $42.7 \pm 37.0$ & $32.3 \pm 27.5$ & 0.24 \\
\hline & & Multiple steps & $34.4 \pm 29.5$ & $39.6 \pm 33.8$ & 0.49 \\
\hline & & Arm movement & $26.0 \pm 25.8$ & $21.9 \pm 32.6$ & 0.70 \\
\hline & & Limb collisions & $20.8 \pm 25.5$ & $21.9 \pm 27.0$ & 0.89 \\
\hline \multirow{5}{*}{$\begin{array}{l}\text { Constrained } \\
\text { (try not to step) }\end{array}$} & \multirow{5}{*}{$\begin{array}{l}\text { No step, Perturbation, } \\
\mathrm{m} / \mathrm{s}^{2}\end{array}$} & 1.0 & $68.8 \pm 38.2$ & $89.1 \pm 22.3$ & $0.002^{* *}$ \\
\hline & & 1.5 & $35.9 \pm 34.1$ & $60.9 \pm 40.8$ & \\
\hline & & 2.0 & $4.7 \pm 10.1$ & $15.6 \pm 30.1$ & \\
\hline & & 2.5 & 0.0 & $1.6 \pm 6.3$ & \\
\hline & & 3.0 & 0.0 & 0.0 & \\
\hline \multicolumn{2}{|c|}{ Cued forward-step } & Extra lateral steps & $13.8 \pm 17.5$ & $3.8 \pm 8.1$ & $0.04^{*}$ \\
\hline
\end{tabular}

$3.0 \mathrm{~m} / \mathrm{s}^{2}$ ), but were often able to avoid stepping at the smaller magnitudes (1.0, 1.5 and $2.0 \mathrm{~m} /$ $\mathrm{s}^{2}$ ) (Table 3, Figure 3). Two-way repeated-measures ANOVA indicated that WBOS footwear improved ability to stabilize the body without stepping $(p=0.002)$, with the size of effect depending on perturbation magnitude (footwearby-magnitude interaction: $p=0.057)$. Depending on the perturbation magnitude, the frequency of stepping was reduced by up to $25 \%(64.1 \%$ of NBOS trials vs $39.1 \%$ of WBOS trials, at the lateral perturbation magnitude of $1.5 \mathrm{~m} / \mathrm{s}^{2}$ ).

For the 'cued forward-step' trials (subjects required to respond to backward platform translation by taking a single step forward over an obstacle and landing the foot on a target), subjects were generally able to clear the obstacle and to land the foot on the target line; however, they re-

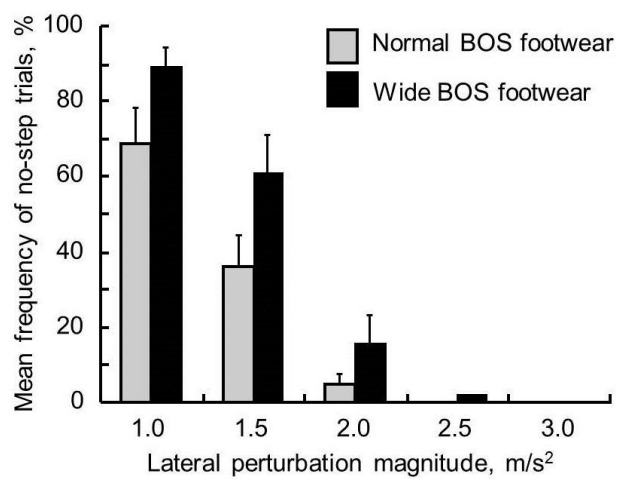

Figure 3. Percentage of no-step trials in 'constrained' lateral balance-perturbation tests (subjects instructed to try not to step); the error bars represent standard errors quired one or more extra lateral steps to recover equilibrium in $\sim 8 \%$ of trials. WBOS footwear reduced the frequency of trials in which one or more extra lateral steps occurred $3.8 \%$ of WBOS trials versus $13.8 \%$ of NBOS trials; $\mathrm{p}=0.04$ ).

\section{Discussion}

The findings provide evidence that a small degree of widening of the footwear outer sole can improve specific aspects of lateral stability of older adults. Specifically, the results support our hypotheses that WBOS footwear could enhance the ability to recover balance without stepping when responding to lateral perturbation, and improve the ability to maintain lateral stability during the execution of forward-step perturbation reactions. The results also support our hypothesis that such benefits could be achieved without adversely affecting gait and mobility, and without increasing the frequency of limb collisions during lateral step reactions. The results do not, however, provide any evidence to support our hypothesis that WBOS footwear would reduce the tendency to take multiple steps in responding to lateral perturbation.

It should be noted that these results were based on multiple statistical analyses. Performing multiple analyses increases the risk of false positives, i.e. the probability of identifying a significant difference due to chance alone. A Bonferroni correction is commonly used to avoid this problem; however, some have noted that this approach is overly conservative and increases the risk of false negatives ${ }^{30}$. Using the Bonferroni correction, our critical p-value is reduced from 0.05 to 0.002 . The finding pertaining to the ability to recover balance without stepping remains statistically significant $(p<0.002)$, but the apparent effect on lateral 
stability during forward-step reactions $(p<0.04)$ does not. Therefore, if one wishes to be conservative, the latter finding should be interpreted only as evidence for a possible trend in the data.

Presumably, the beneficial effects of the WBOS footwear occurred because the increase in lateral BOS limits accommodated increased lateral COM and COP excursion and enabled larger stabilizing moments to be generated ${ }^{3,17}$. Such effects could be sizeable in conditions where the width of the BOS was relatively small, i.e. during bipedal stance (as in the 'constrained' try-not-to-step trials) or during the landing phase of a forwardstep reaction (as in the 'cued forward-step' trials). In contrast, the new BOS established by a lateral step reaction can lead to a much larger change in the BOS width, with respect to the relatively small increase in BOS width provided by the WBOS footwear. This may explain the failure to see any reduction in the frequency of multiple-step responses when wearing the WBOS footwear.

In theory, it is also possible that the failure to see a significant footwear effect on the frequency of multi-step responses was due to footwearrelated changes in response strategy; however, the present data do not support this. On average, there was no significant difference between NBOS and WBOS trials in terms of the pattern of stepping (frequency of crossover versus sidestep-sequence), nor was there any difference in the frequency of arm reactions (which might have provided additional stabilization).

As noted earlier, there was no evidence that the WBOS footwear adversely affected gait and mobility; however, the gait tests did show that WBOS footwear increased stride width. This may reflect an adaptation to avoid feet collisions during walking. One possible way to avoid the need for such an adaptation would be to restrict the widening to the lateral margin of the shoe; however, further work is needed to determine whether this design change would compromise the stabilizing benefits of the WBOS footwear. Further work is also needed to determine the optimum increment in sole width to improve lateral stability without compromising mobility and to determine whether WBOS footwear can actually reduce risk of experiencing lateral falls in daily life.

Ultimately, we envision that increased sole width could be incorporated as an integral feature of the shoe or boot design (Figure 1a). It may also be possible to increase the effective sole width of existing shoes or boots by developing an addon consumer product that straps on or fits over the existing shoe. For the purposes of this initial "proof-of-principle" study, we adopted the latter approach and implemented it in the lab simply by taping polystyrene blocks onto rubber overshoes (Figure 1b). This approach was inexpensive and expedient, and had the further advantage of allowing subjects to wear their own comfortable walking shoes, to which they were well accustomed; however, it is possible that inter-subject variation in other shoe design features may have influenced the degree to which the BOS widening affected their balance-recovery reactions. Further research is needed to identify the optimal combination of shoe-design features.

We elected to focus this initial study on a relatively homogenous cohort of healthy community-dwelling older adults. There is considerable evidence that many such individuals have impaired balance-recovery reactions and may be at increased risk of falls $\mathrm{s}^{7-10}$; hence, stabilizingfootwear could well be of benefit to this demographic. Of course, older adults having more pronounced balance impairments or disorders may well benefit the most from improved footwear, and further research is needed to examine the effects of widened footwear in such populations.

Although the WBOS footwear improved specific aspects of lateral stability of older adults, the acceptability from the user standpoint is also important. In the present study, questionnaires were administered after completion of the experimental trials. Participants were asked "to what extent would you be willing to wear shoes like the WBOS footwear tested", using a rating scale ranging from 1 (not at all) to 7 (very much). The mean (SD) response was 5.4 (1.7), which suggests that a sizeable proportion of older adults may be willing to wear footwear with a widened outsole. However, further research is needed to examine this issue and the various factors such as aesthetic appearance that affect compliance.

\section{Conclusion}

This initial study provides evidence that a small increase in footwear sole width can improve some aspects of lateral stability in older adults, without compromising mobility and agility. These findings support the viability of using widened footwear as an intervention to improve balance in older adults. This type of design modification would be relatively simple and inexpensive for footwear manufacturers to implement; however, further work is needed to determine the optimal footwear design, to assess user compliance, and to determine whether such footwear can actually reduce risk of lateral falls in daily life. Further research is also needed to test populations with more severe balance impairments. 


\section{Acknowledgements}

Funding: A Grant-in-Aid for the Young Scientists (B) (22760110), Grant-in-Aid for Scientific Research (C) (25420080), the Excellent Young Researchers Overseas Visit Program from the Japan Society for the Promotion of Science (JSPS), Canadian Institutes of Health Research (MAT-91865). Infrastructure: Toronto Rehab Institute, Canadian Foundation for Innovation, Ontario Innovation Trust, Ministry of Research and Innovation, Sunnybrook Research Institute. We thank A. Liggins and S. Middleton for their help.

\section{References}

1. Cummings SR, Nevitt MC. Non-skeletal determinants of fractures: the potential importance of the mechanics of falls. Osteoporosis International 1994;4(1):S67-70; doi:10.1007/BF01623439

2. Rogers MW, Mille ML: Lateral stability and falls in older people. Exercise and Sport Science Reviews 2003;31(4):182-187

3. Maki BE, Mcllroy WE. Effects of aging on control of stability. In: Luxon L, Martini A, Furman J, Stephens D, editors, A Textbook of Audiological Medicine: Clinical Aspects of Hearing and Balance. London: Martin Dunitz; 2003; pp 671-690

4. Pai YC, Patton J. Center of mass velocity-position predictions for balance control. Journal of Biomechanics 1997;30(4):347-354; doi:10.1016/S00219290(96)00165-0

5. Maki BE, Mcllroy WE, Fernie GR. Change-in-support reactions for balance recovery: control mechanisms, age-related changes and implications for fall prevention. IEEE Engineering in Medicine and Biology Magazine 2003;22(2): 20-26; doi:10.1109/ MEMB.2003.1195691

6. Maki BE, Mcllroy WE, Perry SD. Influence of lateral destabilization on compensatory stepping responses. Journal of Biomechanics 1996;29(3):343353; doi:10.1016/0021-9290(95)00053-4

7. Maki BE, Edmondstone MA, Perry SD, Heung E, Quant S, Mcllroy WE. Control of rapid limb movements for balance recovery: do age-related changes predict falling risk? In: Duysens J, SmitsEngelsman BCM, Kingma $\mathrm{H}$, editors, Control of Posture and Gait. Maastricht: International Society for Postural and Gait Research; 2001; pp 126129

8. Maki BE, Mcllroy WE. Control of rapid limb movements for balance recovery: age-related changes and implications for fall prevention. Age and Ageing 2006;35(Suppl 2):ii12-ii18; doi:10.1093/ageing/ afl078

9. Hilliard MJ, Martinez KM, Janssen I, Edwards B, Mille ML, Zhang Y, Rogers MW. Lateral balance factors predict future falls in community-living older adults. Archives of Physical Medicine and Rehabilitation 2008;89(9):1708-1713; doi:10.1016/j. apmr.2008.01.023

10. Sturnieks DL, Menant J, Delbaere K, Vanrenterghem J, Rogers MW, Fitzpatrick RC, Lord SR. Force-controlled balance perturbations associated with falls in older people: a prospective cohort study. PLoS One 2013;8(8):e70981; doi:10.1371/ journal.pone.0070981
11. Mille ML, Johnson-Hilliard M, Martinez KM, Zhang Y, Edwards BJ, Rogers MW. One step, two steps, three steps more ... Directional vulnerability to falls in community-dwelling older people. Journal of Gerontology: Medical Sciences 2013;68(12):1540-1548; doi:10.1093/gerona/ glt062

12. Carbonneau E, Smeesters C. Effects of age and lean direction on the threshold of single-step balance recovery in younger, middle-aged and older adults. Gait \& Posture 2014;39(1):365-371; doi:10.1016/j.gaitpost.2013.08.013

13. Maki BE, Edmondstone MA, Mcllroy WE. Agerelated differences in laterally directed compensatory stepping behavior. Journal of Gerontology: Medical Sciences 2000;55(5):M270-277; doi:10.1093/gerona/55.5.M270

14. Mille ML, Johnson ME, Martinez KM, Rogers MW. Age-dependent differences in lateral balance recovery through protective stepping. Clinical Biomechanics 2005;20(6):607-616; doi:10.1016/j. clinbiomech.2005.03.004

15. Mansfield A, Peters AL, Liu BA, Maki BE. Effect of a perturbation-based balance training program on compensatory stepping and grasping reactions in older adults: a randomized controlled trial. Physical Therapy 2010;90(4):476-491; doi:10.2522/ ptj.20090070

16. Mcllroy WE, Maki BE. Age-related changes in compensatory stepping in response to unpredictable perturbations. Journal of Gerontology: Medical Sciences 1996;51(6):M289-M296; doi:10.1093/ gerona/51A.6.M289

17. Winter DA, Prince F, Frank JS, Powell C, Zabjek KF. Unified theory regarding $A / P$ and $M / L$ balance in quiet stance. Journal of Neurophysiology 1996;75(6):2334-2343

18. Brecht JS, Chang MW, Price R, Lehmann J. Decreased balance performance in cowboy boots compared with tennis shoes. Archives of Physical Medicine and Rehabilitation 1995;76(10):940-946; doi:10.1016/S0003-9993(95)80071-9

19. Lord SR, Bashford GM. Shoe characteristics and balance in older women. Journal of the American Geriatrics Society 1996;44(4):429-433

20. Lord SR, Bashford GM, Howland A, Munro B. Effects of shoe collar height and sole hardness on balance in older women. Journal of the American Geriatrics Society 1999;47(6):681-684; doi:10.1111/j.1532-5415.1999.tb01589.x

21. Robbins SE, Gouw GJ, McClaran J. Shoe sole thickness and hardness influence balance in older men. Journal of the American Geriatrics Society 1992;40(11):1089-1094

22. Menant JC, Steele JR, Menz HB, Munro BJ, Lord SR. Effects of footwear features on balance and stepping in older people. Gerontology 2008;54(1):18-23; doi:10.1159/000115850

23. Bohannon RW. Comfortable and maximum walking speed of adults aged 20-79 years: reference values and determinants. Age and Ageing 1997;26(1):15-19; doi:10.1093/ageing/26.1.15

24. Liu CS, Hsu HM, Cheng WL, Hsieh M. Clinical 


\section{Footwear width and balance}

and molecular events in patients with MachadoJoseph disease under lamotrigine therapy. Acta Neurologica Scandinavica 2005;111(6):385-390; doi:10.1111/j.1600-0404.2005.00405.x

25. Podsiadlo D, Richardson S. The timed "Up \& $\mathrm{Go}^{\prime \prime}$ : a test of basic functional mobility for frail elderly persons. Journal of the American Geriatrics Society 1991;39(2):142-148; doi:10.1111/j.1532-5415.1991.tb01616.x

26. Shumway-Cook A, Brauer S, Woollacott M. Predicting the probability for falls in communitydwelling older adults using the Timed Up \& Go Test. Physical Therapy 2000;80(9):896-903

27. Simpson JM, Worsfold C, Reilly E, Nye N. A standard procedure for using TURN180: Testing dynamic postural stability among elderly people. Physiotherapy. 2002;88(6):342-353; doi:10.1016/ S0031-9406(05)60747-X

28. Maki BE, Mcllroy WE. The role of limb movements in maintaining upright stance: the "change-in-support" strategy. Physical Therapy 1997;77(5):488-507

29. Zettel JL, Mcllroy WE, Maki BE. Effect of competing attentional demands on perturbation-evoked stepping reactions and associated gaze behavior in young and older adults. Journal of Gerontology: Medical Sciences 2008;63(12):1370-1379

30. Feise RJ. Do multiple outcome measures require p-value adjustment? BMC Medical Research Methodology 2002;2:8; doi:10.1186/1471-2288-2-8 